\title{
Correction to: Possible Mechanisms of Long-Term Trend of June Rainfall over the Korean Peninsula
}

\author{
Hyeran Lee $^{1} \cdot$ Hwan-Jin Song $^{2}$ (D) Byung-Ju Sohn ${ }^{1}$
}

Published online: 18 February 2020

(C) The Author(s) 2020

\section{Correction to: Asia-Pacific Journal of Atmospheric Sciences https://doi.org/10.1007/s13143-019-00170-5}

The article "Possible Mechanisms of Long-Term Trend of June Rainfall over the Korean Peninsula", written by Hyeran Lee, Hwan-Jin Song and Byung-Ju Sohn, was originally published electronically on the publisher's internet portal on 08 January 2020 without open access.

With the author(s)' decision to opt for Open Choice the copyright of the article changed on 18 February 2020 to (C) The Author(s) 2020 and the article is forthwith distributed under a Creative Commons Attribution 4.0 International License (https://creativecommons.org/licenses/by/4.0/), which permits use, sharing, adaptation, distribution and reproduction in any medium or format, as long as you give appropriate credit to the original author(s) and the source, provide a link to the Creative Commons licence, and indicate if changes were made.

The original article has been corrected.

The online version of the original article can be found at https://doi.org/ 10.1007/s13143-019-00170-5

Hwan-Jin Song

hwanjinsong@gmail.com

1 School of Earth and Environmental Sciences, Seoul National University, Seoul, South Korea

2 National Institute of Meteorological Sciences, Korea Meteorological Administration, Jeju, South Korea 